\title{
A New Gold Resistance Alloy
}

\section{A STUDY OF THE GOLD-PALLADIUM-VANADIUM SYSTEM}

\section{Franz Sperner}

W. C. Heraeus GmbH, Hanau, West Germany

For precision potentiometers a high resistivity is required together with a low temperature coefficient of resistance, a low thermoelectric force against copper, low contact resistance and good wearing characteristics. This article describes the development of a goldpalladium-vanadium alloy that combines all these properties.

In industrial measurement and control techniques wire-wound potentiometers are widely used as essential means of converting linear or angular movements into electrical impulses. The quality of the potentiometer is therefore a determining factor in the accuracy of the entire control or measuring system, and for this reason a high degree of constancy and reliability is required, generally over a long working period and at varying temperatures in industrial atmospheres. The base metal resistance alloys cannot meet these requirements, and noble metal alloys must be chosen for their stability and freedom from tarnish or corrosion.

In order to reduce the size and weight of potentiometers resistance alloys are required with a high ohmic resistance but yet with a low temperature coefficient of resistance and a low thermoelectric voltage against copper. A low contact resistance is also necessary, as are resistance to wear and corrosion, while the alloys should be readily workable into the
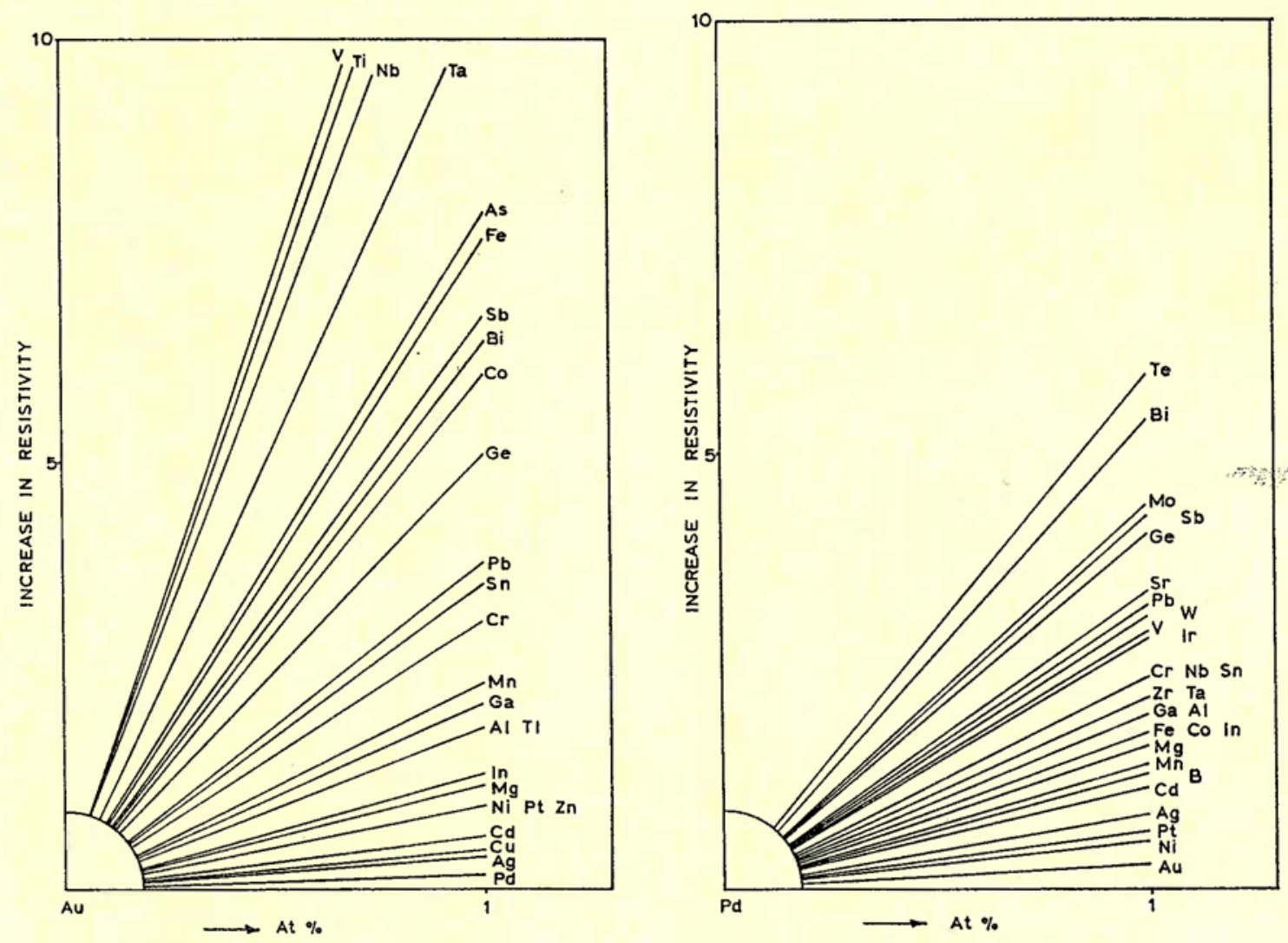

Fig. 1 A graphic representation of the effects on electrical resistivity of adding 1 atomic per cent of other elements to gold and palladium respectively 
form of fine wire. Another important factor is their ease of soldering.

Extensive investigations have been made with alloys based on platinum, palladium and gold, resulting in a great number of alloys having resistivities ranging from 10 to 180 microhm $\mathrm{cm}$. A comprehensive review of the alloys based upon gold was recently given by Dr. A. S. Darling in this journal (1), the alloys there described having resistivities ranging up to 100 microhm $\mathrm{cm}$. Clearly there is a need for still higher resistivities but hitherto this requirement has not been fulfilled. As a result of a study of the gold-palladium-vanadium system in these laboratories a new gold-based alloy has now been developed with a resistivity of more than 200 microhm $\mathrm{cm}$ and meeting virtually all the other requirements.

\section{Alloying Additions and Resistivity}

A good indication of possible alloying additions to the noble metals is given by the increase in resistivity obtained by adding one atomic per cent of each element. In Figure 1 a graphic representation is given of values from the literature for additions to gold and palladium. The general conclusion to be drawn from these diagrams is that an increase in resistivity of more than 10 microhm $\mathrm{cm}$ per atomic per cent can be obtained with gold by the addition of vanadium, titanium, niobium and tantalum. For palladium an increase of 3.2 microhm $\mathrm{cm}$ per cent of vanadium has been determined, 2.96 microhm $\mathrm{cm}$ for niobium and 2.44 microhm $\mathrm{cm}$ for tantalum.

\section{The Binary Systems Au-V, Pd-V and Au-Pd}

Apart from the increase in resistivity obtained by the addition of other elements an adequate solid solubility in the basis metal is essential for the utilisation of such increases. The equilibrium system, investigated by Köster and Nordskog (2) and reproduced in Figure 2, shows a large solubility range for vanadium up to 59 atomic per cent, with a temperature-dependent solubility line that reduces this value to about 48 atomic per cent (about 18 weight per cent) at ambient temperature. In this range the ordered structures $\mathrm{Au}_{4} \mathrm{~V}$ and $\mathrm{Au}_{2} \mathrm{~V}$ are formed at low temperatures.

The palladium-vanadium system was described by Köster and Haehl (3) and is shown in Figure 3. This is analogous to the gold-vanadium diagram, having a large range of solid solubility and the ordered structures $\mathrm{Pd}_{3} \mathrm{~V}$ and $\mathrm{Pd}_{2} \mathrm{~V}$ at low temperatures.

The physical properties of gold-vanadium alloys were studied by Köster, Kehrer and Rothenbacher (4), who reported the electrical conductivity, the

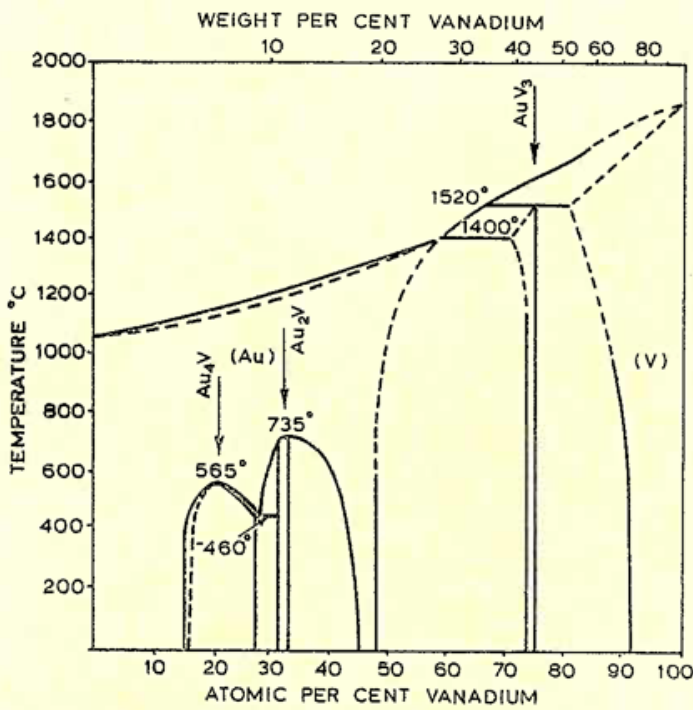

Fig. 2 The equilibrium diagram of the binary goldvanadium system. (After Köster and Nordskog)

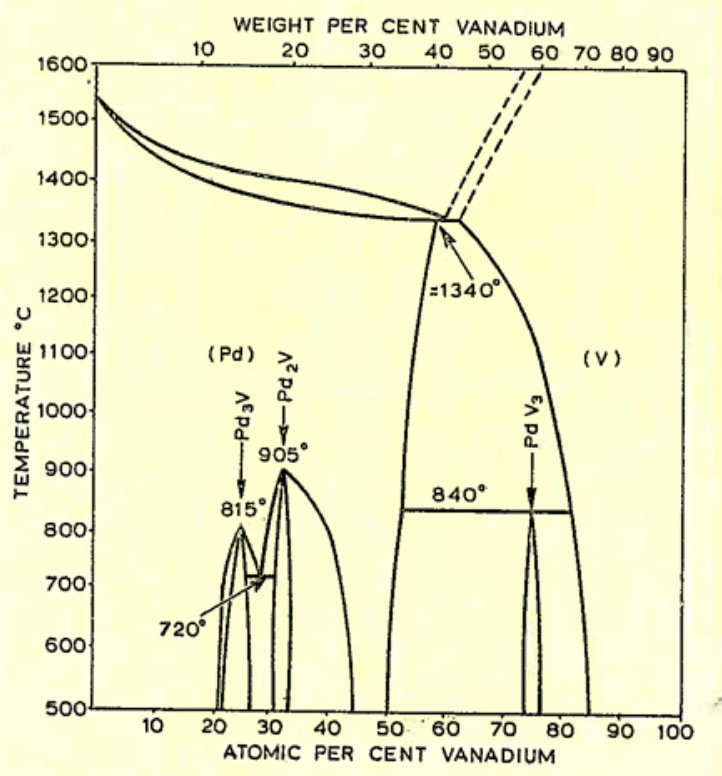

Fig. 3 The equilibrium diagram of the binary palladium-vanadium system. (After Köster and Haehl)

temperature coefficient between $-183^{\circ}$ and $-60^{\circ} \mathrm{C}$, the thermal e.m.f. and the Hall constant for alloys with up to 20 atomic (6.1 weight) per cent. We have extended these investigations up to 48 atomic (18 weight) per cent, with the results given in Figure 4. It will be seen that the resistivity rises steeply with small additions of vanadium, attains a broad maximum of 195 microhm $\mathrm{cm}$ at about 10 weight per cent and over a long range and then decreases slowly to 167 microhm $\mathrm{cm}$ at 18 weight per cent vanadium. 


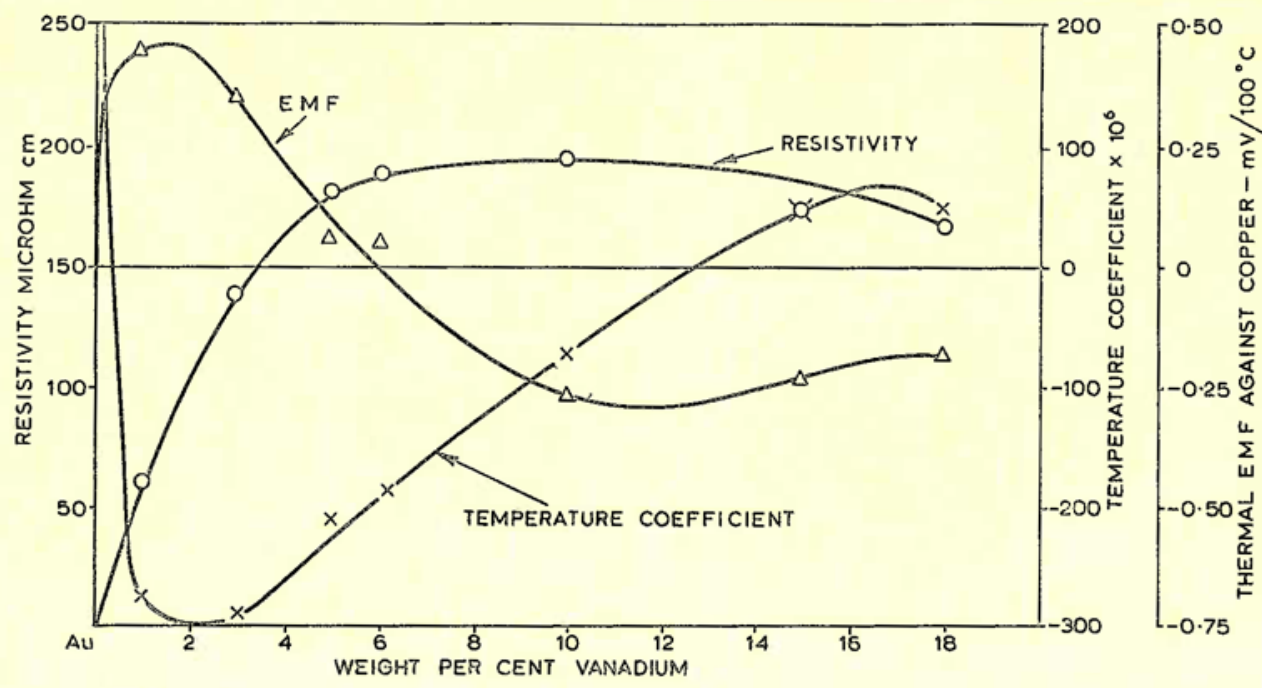

Fig. 4. The resistivity, temperature coefficient of resistance and thermal e.m.f.s againgt copper of binary gold-vanadium alloys

The temperature coefficient of resistance $(0$ to $100^{\circ} \mathrm{C}$ ) becomes distinctly negative at 1 weight per cent vanadium, passes through a minimum value at approximately 2 weight per cent and then rises steadily with increasing vanadium content. At approximately 12 weight per cent vanadium the curve crosses the zero line, reaches a positive value of $49 \times 10^{-6}$ per deg $C$ at 15 per cent and drops to $43 \times 10^{-6}$ per deg $C$ at 18 per cent vanadium.

The thermal e.m.f. against copper of these alloys at $100^{\circ} \mathrm{C}$ increases to 0.454 millivolt with the addition of 1 weight per cent vanadium, passes through the zero line at approximately 6.5 weight per cent and then falls further to negative values.
The same properties for the palladium-vanadium alloys are shown in Figure 5. The resistivity rises with the addition of vanadium and reaches a maximum of 134 microhm $\mathrm{cm}$ at around 10 weight per cent, dropping to 107 microhm $\mathrm{cm}$ at 13.8 weight per cent vanadium. The temperature coefficient falls sharply from the value for pure palladium to a figure of $306 \times 10^{-6}$ at 5 weight per cent vanadium, falls further to pass through a minimum and rise again. The thermal e.m.f. against copper increases to 1.78 millivolt with 5 weight per cent vanadium and then falls steeply and crosses the zero line at around 9 per cent vanadium, decreasing further with greater additions.

The gold-palladium system with particular reference to resistivity and temperature coefficient was recently described by Darling (1).

This system has been widely used as a basis for the development of gold alloys in which the dual requirements of high resistivity and low temperature coefficient are obtained, but the peak value of resistivity is only some 28 microhm $\mathrm{cm}$.

The thermal e.m.f. of these alloys against copper is always negative and reaches its highest value at approximately 50 weight per cent palladium, corresponding with the highest value of resistivity. 


\section{The Ternary System Au-Pd-V}

The ternary gold-palladium-vanadium alloys were investigated by Köster, Rave and Takeuchi (5) along the line 9 atomic per cent vanadium - 9 atomic per cent palladium. They found that the resistivity increased by adding palladium to the gold-vanadium alloy, and it therefore seemed advisable to study alloys having a higher vanadium content.

Our values for alloys in the ternary system along the line 5 weight per cent vanadium-gold -5 weight per cent vanadium-palladium are given in Figure 6. The resistivity increases to 187 microhm $\mathrm{cm}$ by the addition of 10 weight per cent palladium and then decreases steadily. The temperature coefficient rises from a high negative value and crosses the zero line at 62.5 weight per cent palladium, at which point the resistivity has dropped to 122 microhm $\mathrm{cm}$.

The behaviour of the thermal e.m.f. on adding palladium to the gold-vanadium system is somewhat unusual. It first becomes highly negative, rises sharply, passes twice through the zero line and then rise steeply. The alloys having a thermal e.m.f. close to zero have a resistivity of 147 to 149 microhm $\mathrm{cm}$.

A further study of the ternary system was carried out on the line 10 weight per cent vanadium-gold- 10 weight per cent vanadium-palladium and the results are given in Figure 7. Here the resistivity is increased from 195 to 218 microhm $\mathrm{cm}$ by the addition of 10 to 15 weight per cent of palladium, the values falling slowly to 134 microhm $\mathrm{cm}$ for 10 weight per cent vanadium-palladium. The temperature coefficient first shows a downward trend to more negative values, returns towards zero and meets the zero line at approximately 30 weight per cent palladium. The thermal e.m.f. also first moves towards more negative values but rises again steeply and passes the zero line at approximately 20 per cent palladium, becoming positive again and then passing back into the negative range, crossing zero again at 32 per cent palladium.

In this ternary system noble metal alloys were found for the first time with a resistivity of more than 200 microhm $\mathrm{cm}$ and at the same time with temperature coefficients and thermal e.m.f. values against copper approaching zero.

Further studies were concerned with the effect of a fourth element on the electrical properties of this system. The results have shown that it is possible to decrease further the temperature coefficient, for example to $-13 \times 10^{-6}$ per deg $\mathrm{C}$ by the addition of cobalt, but the resistivity then falls slightly to 206 microhm $\mathrm{cm}$ while the e.m.f. rises to 0.07 millivolt.

The thermal stability of alloys with the highest resistivity has been carefully studied. After annealing for a long period in air at temperatures up to $300^{\circ} \mathrm{C}$ the values of resistivity, temperature coefficient and thermal e.m.f. remained unchanged, as also do the contact resistance.

These investigations into the system gold-palladium-vanadium have shown that good workable resistance alloys can be produced with a resistivity of more than 200 microhm $\mathrm{cm}$, a temperature coefficient of less than $-30 \times 10^{-6}$ per deg $\mathrm{C}$ and a thermal e.m.f. against copper of less than 0.07 millivolt at $100^{\circ} \mathrm{C}$. The alloys have a Vickers hardness of more than 200 , a tensile strength of more than $74 \mathrm{~kg} / \mathrm{mm}^{2}$ $\left(47\right.$ tons/in ${ }^{2}$ ) and an elongation of more than 30 per cent. These electrical and mechanical values remain constant over a long working period.

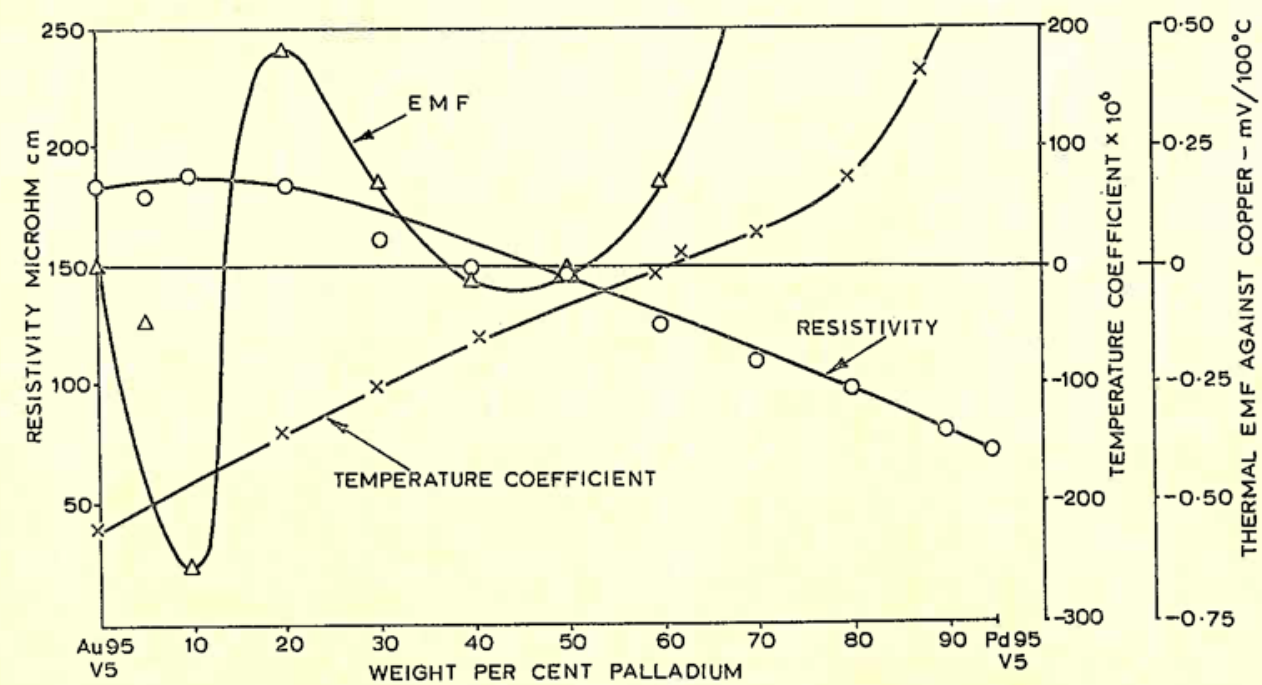

Fig. 6 The resistivity, temperature coefficient and thermal e.m.f.s of alloys in the ternary system with 5 per cent vanadium 


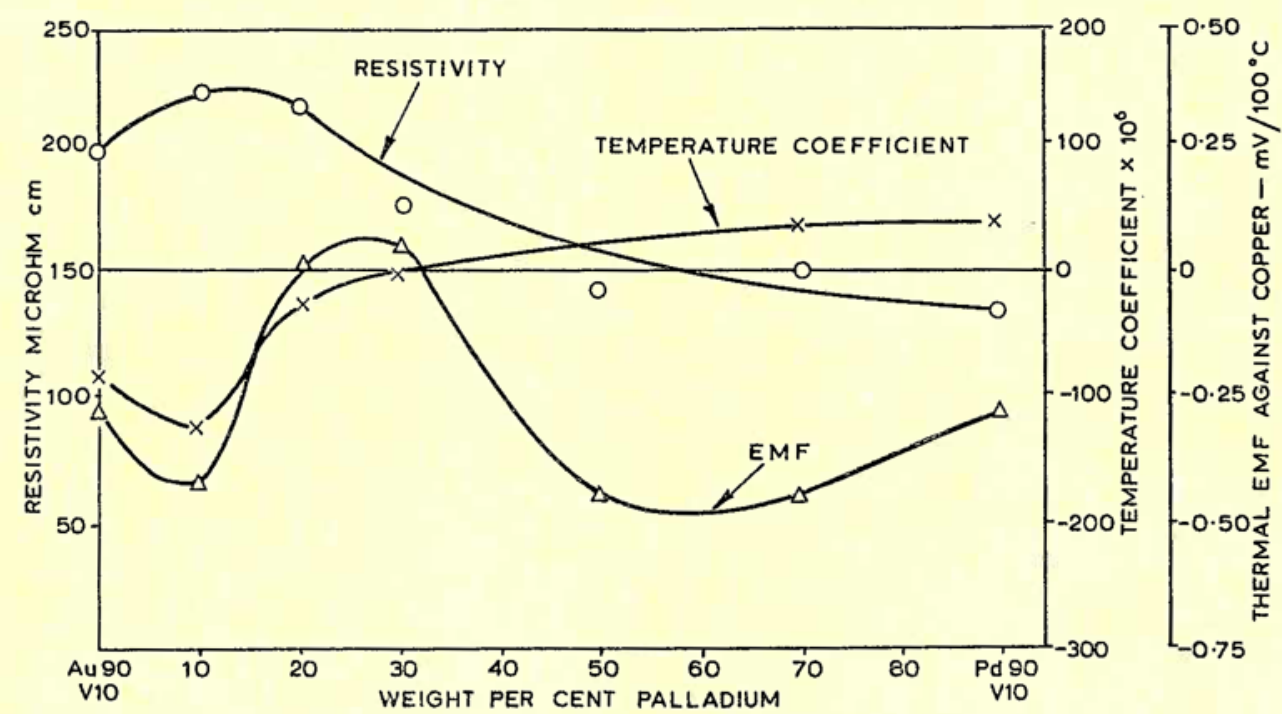

Fig. 7 The resistivity, temperature coefficient and thermal e.m.f.s of alloys in the ternary system with 10 per cent vanadium. At 20 per cent palladium it will be seen that an alloy is obtained having an excellent combination of properties

The alloy chosen for commercial development is that containing 10 per cent vanadium, 20 per cent palladium, balance gold. From the results in Figure 7 it will be readily seen that this material gives the optimum combination of properties, and it is at present undergoing development trials in a number of instrumental applications.

\section{References}

1 A. S. Darling, Gold Bulletin, 1972, 5, (4) 2

2 W. Köster and H. Nordskog, Z. Metallk., 1960, 51, 501

3 W. Köster and W. D. Haeh1, Z. Metallk., 1958, 49, 647

4 W. Köster, H. Kehrer and W. Rothenbacher, Z. Metallk., 1961, 52, 672

5 W. Köster, H. P. Rave and Y. Takeuchi, Z. Metallk., $1962, \mathbf{5 3}, 749$

\section{The Catalytic Properties of Palladium-Gold Alloys}

The view has previously been expressed in this journal that the very properties which make gold both so useful and so attractive in appearance militate against its having widespread and useful catalytic properties. It has, however, a useful role to play in moderating the properties of the much more vigorously active metals, such as platinum and especially palladium, with which it forms a continuous range of solid solutions. A lengthy review on "The Structure and Catalytic Properties of Palladium-Silver and Palladium-Gold Alloys", published recently by Dr E. G Allison and Professor G. C. Bond of Brunel University (1), provides a very full survey of the literature concerning the part which the Group IB metals exercise in altering the characteristics of the more active partner.

The over-riding impression gained from this review is that most of the catalytic work has been performed with forms of alloys which could not possibly be used in industrial processes - foils, wires and evaporated alloy films are frequently mentioned. Only very little seems to have been done using supported palladiumgold alloys, and much of this work stems from the patent literature and is therefore incompletely validated. There is clearly scope for much more research using carefully characterised supported alloys.

There are two theoretical approaches to describing how gold alters the catalytic properties of palladium.
The older idea, first propounded by Sir Neville Mott in the 1930s, states that gold's s-electrons enter the unfilled $d$-band of palladium, with consequent and proven effects on the latter's magnetic susceptibility and possibly on its catalytic capabilities. The newer idea, due to Wolfgang Sachtler of the Shell Laboratories in Amsterdam, suggests that the behaviour of an alloy surface is described by the arithmetic sum of the properties of the separate palladium and gold atoms. Thus for example one palladium atom surrounded by gold atoms will not behave in the same way as when surrounded by its own kind. This has been advanced as an explanation of the truly remarkable increase in selectivity for the oxidation of ethylene to acetaldehyde over alloy powders containing 60 to 85 per cent gold.

A further intriguing notion is that the surface composition of an alloy can change under the influence of adsorption, becoming enriched in whichever component interacts more strongly with the adsorbed species.

The review serves to indicate the wealth of unexplored possibilities which exist for gold to be beneficially employed in tempering the catalytic activity of other metals, notably by improving the selectivity with which intermediate oxidation products are formed from hydrocarbons.

1 E. G. Allison and G. C. Bond, Catalysis Revs., 1972, 7, 233 